\title{
PENGARUH FASHION INVOLVEMENT, SHOPPING LIFESTYLE, HEDONIC SHOPPING VALUE DAN POSITIVE EMOTION TERHADAP IMPULSE BUYING PRODUK FASHION PADA PELANGGAN DUTA MALL BANJARMASIN
}

\author{
Irma Sucidha \\ ASMI Citra Nusantara Banjarmasin \\ Jl. Brigjen Hasan Basri Kampus Unlam Kayu Tangi \\ E-mail: irmasucidhamm@yahoo.com
}

\begin{abstract}
This research is intended to find out and analys the effect between fashion involvement (XI), shopping lifestyle (X2), hedonic shopping value (X3) and positive emotion (X4) as exogenous variable towards impulse buying (Y1) as endogenous variable to the Duta Mall Banjarmasin customer. This study used the quantitative research by spreading questioners to the customer of Duta Mall Banjarmasin who shop about 145 persons. The sample was taken by the purposive sampling method. The measurement of variable used the bipolar adjective scale with the weight scale from 1 to 10. To find out the effect of $X$ variable towards $Y$ variable used Structural Equation Modelling (SEM). The result concluded that (1) there is a negative influence and insignificant variables of fashion involvement (XI) towards impulse buying (Y) in the amount of -7,4\%. (2) shopping lifestyle variable (X2) influence significantly and positive in the amount 72,9\% towards impulse buying $(Y)$, hedonic shopping value variable (X3) influence significantly and positive in the amount 17,2\% towards impulse buying $(Y)$ and (4) positive emotion variable (X4) influence significantly and positive in the amount 17,8\% towards impulse buying $(Y)$.
\end{abstract}

Keywords: Fashion involvement, shopping lifestyle, hedonic shopping value, positive emotion, impulse buying.

\begin{abstract}
Abstrak
Penelitian ini bertujuan untuk mengetahui dan menganalisis pengaruh antara fashion involvement (X1), shopping lifestyle (X2), hedonic shopping value (X3) dan positive emotion (X4) sebagai variabel eksogen terhadap impulse buying (Y1) sebagai variabel endogen pada pelanggan Duta Mall Banjarmasin. Metode penelitian kuantitatif dengan menyebarkan kuisioner kepada pelanggan Duta Mall Banjarmasin sebanyak 145 orang. Sampel diambil dengan menggunakan metode purposive sampling. Pengukuran variabel menggunakan teknik skala bipolar adjective dengan skala bobot dari 1 sampai 10. Untuk mengetahui pengaruh variabel $\mathrm{X}$ terhadap variabel $\mathrm{Y}$ menggunakan teknik analisis Structural Equation Modelling (SEM). Hasil penelitian menyimpulkan bahwa (1) terdapat pengaruh yang negatif dan tidak signifikan dari variabel fashion involvement (X1) terhadap impulse buying (Y) sebesar $-7,4 \%$. (2) variabel shopping lifestyle (X2) berpengaruh signifikan dan positif sebesar 72,9\% terhadap impulse buying $(\mathrm{Y})$, (3) variabel hedonic shopping value (X3) berpengaruh signifikan dan positif sebesar 17,2\% terhadap impulse buying (Y) dan (4) variabel positive emotion (X4) berpengaruh signifikan dan positif sebesar 17,8\% terhadap impulse buying (Y).
\end{abstract}

Kata Kunci: Fashion involvement, shopping lifestyle, hedonic shopping value, positive emotion, impulse buying. 


\section{PENDAHULUAN}

Seiring dengan perkembangan jaman yang semakin modern, hadirlah beberapa Mall di kota Banjarmasin. Salah satunya adalah Banjarmasin Duta Mall yang memberikan rasa aman dan nyaman dalam berbelanja maupun berekreasi meliputi Trade Center, Mall, dan Hotel. Mall ini merupakan pusat perbelanjaan yang dimana letaknya merupakan kawasan perdagangan dan perkantoran yang berarti pasar yang sangat potensial dan strategis untuk berinvestasi. (id.m.wikipedia.org, diakses : 26 Juli 2015).

Hadirnya mall di Banjarmasin menjadikan peluang bisnis bagi para pelaku bisnis terutama dibidang fashion karena banyak pengunjung yang berkunjung ke mall, dimana sebagian besar pengunjung yang berkunjung karena ingin berbelanja pakaian. Hal ini mendorong perusahaan untuk dapat terus mempertahankan eksistensinya yaitu dapat dilakukan dengan cara perusahaan untuk memahami perilaku konsumen, salah satu perilaku konsumen yang sering terjadi di mall adalah impulse buying.

Impulse buying secara umum dikenal sebagai pembelian yang terjadi karena munculnya hasrat (desire) secara tiba-tiba tanpa diikuti dengan proses berpikir mengenai konsekuensi yang kemungkinan akan muncul setelah pembelian. Hawkins, Mothersbaugh, \& Roger (2007) menyatakan bahwa impulse buying/impulse purchase adalah pembelian tidak terencana yang terjadi ketika konsumen melakukan pembelian dengan sedikit pertimbangan atau bahkan tidak ada sama sekali dikarenakan adanya perasaan mendesak secara tiba-tiba untuk memiliki benda tersebut.

Berdasarkan hasil survey yang dilakukan oleh Nielsen (2007), ternyata 85 persen pembelanja di ritel modern (produk fashion) Indonesia cenderung untuk berbelanja sesuatu yang tidak direncanakan (impulse buying: tantangan baru pemilik merek, 2009). Dan dari hasil survey yang dilakukan oleh Sienciety Bussiness Consult, mendapatkan hasil yaitu: di kota-kota besar di Indonesia, hanya sekitar 25 persen yang tidak gemar jalan-jalan atau belanja di mall. Dimana, kemungkinkan keluarga yang tadinya hanya sekedar jalan-jalan dan kemudian berbelanja sangat tinggi. Cuma 12,5 persen keluarga Indonesia yang hanya jalan-jalan. (Sumber: Kolom Ritel 360', KOMPAS, 23 November 2010).

Adapun beberapa faktor lain yang dapat mempengaruhi seseorang ketika melakukan impulse buying, yaitu: fashion involvement, shopping lifestyle, hedonic shopping value dan positive emotion. (Rachmawati, 2009).

\section{TINJAUAN PUSTAKA \\ Landasan Teori \\ Fashion Involvement}

Menurut Kapfferer dan Laurent (1985), dan Kim (2005) dan Martin (1998), Involvement adalah suatu sistem metrik yang sangat menolong dalam menjelaskan perilaku konsumen dan segmen pasar konsumen (Park et al., 2006). Involvement adalah minat atau bagian motivasional yang ditimbulkan oleh stimulus maupun situasi tertentu dan ditunjukkan melalui penampilan. (O'cass, 2004). Secara umum, involvement merupakan konsep yang menjelaskan interaksi antara konsumen dengan suatu produk.

Dalam pemasaran fashion, fashion involvement mengacu pada ketertarikan perhatian dengan kategori produk fashion seperti contohnya pakaian, tas, dan sepatu. Dalam penelitiannya Fairhurst et al., (1989), dan Seo et al., (2001) menemukan bahwa terdapat hubungan positif antara tingkat fashion involvement dan pembelian pakaian 
dimana konsumen dengan fashion involvement yang lebih tinggi memungkinkan membeli pakaian.

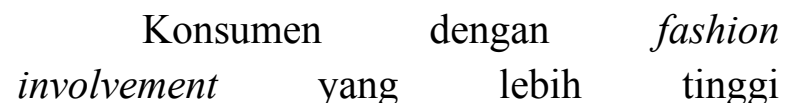
memungkinkan terlibat dalam pembelian impulsif yang berorientasi fashion (Park et al., 2006). O'Cass (2004) dalam penelitiannya menemukan bahwa dalam fashion involvement pada pakaian berhubungan erat dengan karakteristik pribadi (yaitu wanita dan kaum muda) dan pengetahuan fashion, yang mana kemudian mempengaruhi kepercayaan konsumen dalam membuat keputusan pembelian (Park et al., 2006).

\section{Shopping Lifestyle}

Shopping lifestyle merupakan ekspresi tentang lifestyle dalam berbelanja yang mencerminkan perbedaan status sosial. (Betty Jackson, 2004). Shopping lifestyle mengacu pada pola konsumsi yang mencerminkan pilihan seseorang tentang bagaimana cara menghabiskan waktu dan uang.

Shopping lifestyle mengacu pada pola konsumsi yang mencerminkan pilihan seseorang tentang bagaimana cara menghabiskan waktu dan uang. Dalam arti ekonomi, shopping lifestyle menunjukkan cara yang dipilih oleh seseorang untuk mengalokasikan pendapatan, baik dari segi alokasi dana untuk berbagai produk dan layanan, serta alternatif-alternatif tertentu dalam pembedaan kategori serupa (Zablocki dan Kanter, 1976:269-297 dalam dalam Japarianto dan Sugiharto, 2011).

Berdasarkan beberapa definisi di atas, dapat disimpulkan bahwa shopping lifestyle adalah cara seseorang untuk mengalokasikan waktu dan uang untuk berbagai produk, layanan, teknologi, fashion, hiburan dan pendidikan. Shopping lifestyle ini juga ditentukan oleh beberapa faktor antara lain sikap terhadap merek, pengaruh iklan dan kepribadian.

\section{Hedonic Shopping Value}

Menurut Sherry (1990) dalam Scarpi (2006) hedonisme berasal dari bahasa Yunani yaitu hedone yang artinya kesenangan atau kenikmatan. Konsumsi hedonik mencerminkan nilai pengalaman berbelanja seperti fantasi, arousal, stimulasi-sensori, kenikmatan, kesenangan, keingintahuan, dan hiburan. Menurut Semuel (2004), kecenderungan konsumsi hedonis mencerminkan instrument yang menyajikan secara langsung manfaat dari suatu pengalaman dalam melakukan pembelanjaan, seperti kesenangan dan hal-hal baru.

Hedonic shopping value merupakan hal yang lebih meriah dan menyenangkan yang mencerminkan nilai hiburan dan emosional yang berasal dari belanja adalah sesuatu hal yang menyenangkan dan sebagai pelarian atau petualangan. (Babin et al., 1994).

Selain itu, sedikitnya ada 6 pengalaman ketika berbelanja yang berpotensi sebagai sumber dari kesenangan ketika berbelanja tersebut (Pleasure and Hedonic Shopping), seperti: berburu harga (hunting bargain), melihat-lihat barang (browsing), Stimulasi pancaindera (Sensory Stimulation), bercampur dengan orang lain (Mingling with others, perasaan senang menjadi orang yang dimanjakan (Being Pampered), dan pengalaman kinestetic.

\section{Positive Emotion}

Positive emotion dapat didatangkan dari sebelum terjadinya mood seseorang, 
kecondongan sifat afektif seseorang dan reaksi pada lingkungan yang mendukung seperti ketertarikan pada item barang ataupun adanya promosi penjualan (Rachmawati, 2009). Faktor perasaan atau emosi merupakan konstruk yang bersifat temporer karena berkaitan dengan situasi atau objek tertentu (Hetharie, 2011). Emosi juga dapat mempengaruhi suasana hati dan merupakan faktor penting dalam pengambilan keputusan konsumen.

Penciptaan positive emotion pada konsumen mengenai satu produk atau artikel bahkan lingkungan toko dapat meningkatkan motif konsumen dalam melakukan impulse buying (Amiri et al., 2012).

Perasaan atau mood yang dialami seseorang yang membawa dampak pada keinginan yang sangat besar untuk melakukan impulse buying. Emosi sangat mempengaruhi tingkah laku seseorang dalam membeli suatu barang termasuk pembelian secara impulsif (Beatty and Ferrell, 1998; Hausman, 2000; Rook and Gardner, 1993; Youn and Faber, 2000).

\section{Impulse Buying}

Menurut Rook dan Gardner (1993) dalam Kacen dan Lee (2002) pembelian impulsif didefiniskan sebagai pembelian yang tidak direncanakan dengan karakteristik pembuatan keputusan yang relatif cepat dan merupakan sebuah bias subyektif yang mendukung keinginan untuk memiliki dengan segera.

Blacwell (1982), mendefinisikan unplanned buying adalah suatu tindakan pembelian yang dibuat tanpa direncanakan sebelumnya atau keputusan pembelian dilakukan pada saat berada di dalam toko. Coob dan Hayer (1986), mengklasifikasikan suatu pembelian impulsif terjadi apabila tidak terhadap tujuan pembelian merek tertentu atau kategori produk tertentu pada saat masuk ke dalam toko. Beberapa peneliti pemasaran beranggapan bahwa impulse sinonim dengan unplanned ketika para psikolog dan ekonom memfokuskan pada aspek irasional atau pembeli impulsif murni (Bayley dan Nancarrow, 1998).

Keputusan pembelian yang dilakukan belum tentu direncanakan, terdapat pembelian yang tidak direncanakan (impulsive buying) akibat adanya rangsangan lingkungan belanja. Implikasi dari lingkungan belanja terhadap perilaku pembelian mendukung asumsi bahwa jasa layanan fisik menyediakan lingkungan yang mempengaruhi perilaku konsumen, dihubungkan dengan karakteristik lingkungan konsumsi fisik (Bitner, Booms, dan Tetreault, 1990).

\section{Penelitian Terdahulu}

Japarianto dan Sugiharto (2012) menggunakan variabel penelitian terdiri dari varibel shopping lifestyle (X1) dan variabel fashion involvement (X2) dan variabel impulse buying (Y). Hasil penelitian menyatakan kedua variabel tersebut berpengaruh signifikan terhadap impulse buying.

Penelitian kedua dilakukan oleh Dhurup (2014) menggunakan variabel penelitian terdiri dari variabel hedonism (X1), variabel emotional gratification (X2), dan fashion involvement (X3) dan impulse buying (Y). Hasil penelitian menyatakan ketiga variabel tersebut berpengaruh signifikan terhadap impulse buying.

Penelitian ketiga oleh Rachmawati (2009) menggunakan variabel penelitian ini terdiri dari hedonic shopping value (X1), positive emotion (Y1) dan impulse buying 
(Y2). Hasil penelitian menyatakan kedua variabel tersebut berpengaruh signifikan terhadap impulse buying.

\section{Hipotesis Penelitian}

H1: Faktor fashion involement berpengaruh positif terhadap impulse buying pelangganDuta Mall Banjamasin.

$\mathrm{H} 2$ : Faktor shopping value berpengaruh positif terhadap impulse buying pelanggan Duta Mall Banjamasin.
H3: Faktor hedonic shopping value berpengaruh positif terhadap impulse buying pelanggan Duta Mall Banjarmasin.

H4: Faktor positive emotion berpengaruh positif terhadap impulse buying pelanggan Duta Mall Banjarmasin.

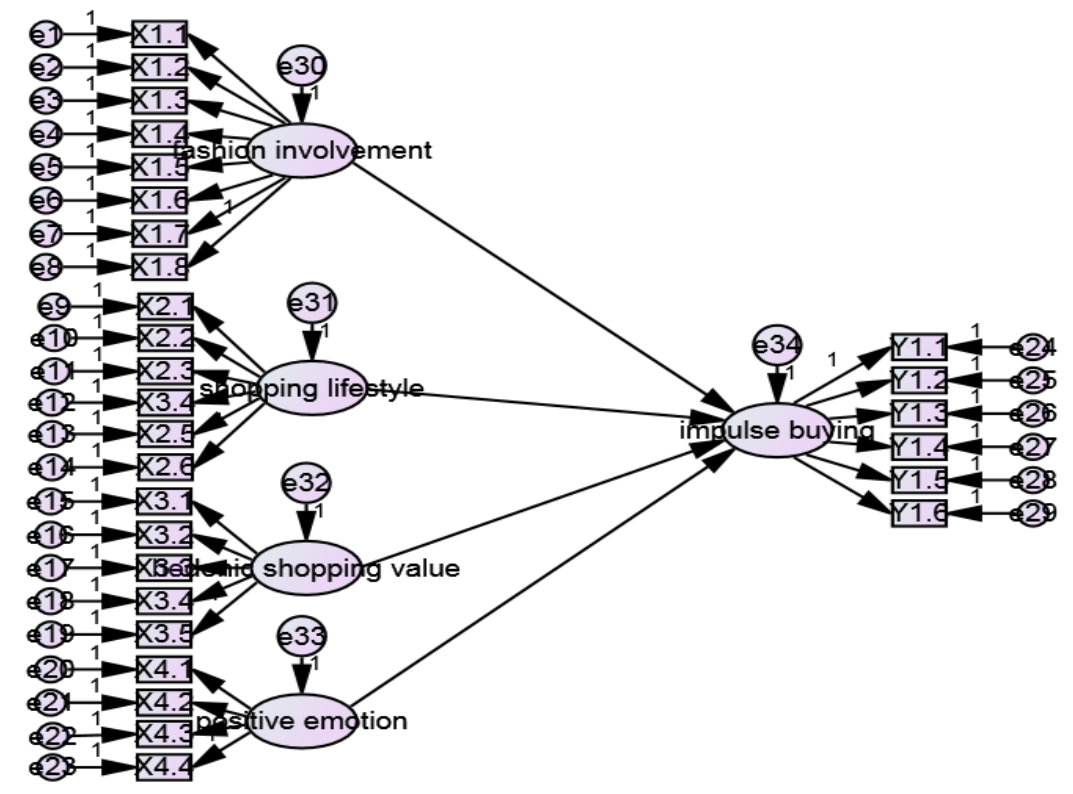

Gambar 1. Kerangka Konseptual Dan Hipotesis

Sumber : Model diolah dan dikembangkan untuk penelitian ini

\section{METODE PENELITIAN}

\section{Jenis Penelitian}

Berdasarkan perumusan masalah dan tujuan penelitian yang ingin dicapai maka penelitian yang digunakan adalah metode penelitian kuantitatif yang digunakan untuk mendapatkan data yang terjadi pada masa lampau atau saat ini, tentang keyakinan, pendapat, karakteristik, perilaku, hubungan variabel untuk menguji beberapa hipotesis dari populasi tertentu, teknik pengumpulan data dengan pengamatan (wawancara atau kuesioner) tidak mendalam dan hasil penelitian cenderung untuk digeneralisasikan (Sugiono, 2013).

Penelitian ini termasuk kausal karena penelitian ini merupakan penelitian sebabakibat yang akan membuktikan ada atau tidaknya pengaruh fashion involvement, shopping lifestyle, hedonic shopping value, dan positive emotion terhadap impulse buying produk fashion pelanggan Duta Mall Banjarmasin.

\section{Populasi dan Ukuran Sampel Penelitian}

Populasi dalam penelitian ini adalah pengunjung pusat perbelanjaan Duta Mall Banjarmasin sejumlah 145 orang. 
Teknik Pengumpulan Data

Penelitian ini menggunakan teknik survey dengan membagikan angket sejumlah sample yang sudah dihitung dengan menggunakan skala pengukuran bipolar adjective dengan skala $1-10$.

\section{Metode Analisis Data}

Adapun teknik pengolahan data dalam penelitian ini menggunakan pendekatan metode analisis SEM (Structural Equation Model). Penelitian ini menggunakan metode analisis SEM karena SEM dapat mengidentifikasi dimensi-dimensi dari sebuah konstruk dan pada saat yang sama mampu mengukur pengaruh atau derajat hubungan antar faktor yang telah diidentifikasi dimensi-dimensinya.

\section{HASIL DAN PEMBAHASAN}

Berdasarkan penilaian goodness of fit di bawah dapat dilihat bahwa hasil estimasi menunjukkan semua nilai masih belum memenuhi kriteria cut value yang disarankan. Dengan demikian dapat disimpulkan bahwa model ini dinyatakan jelek dan harus dilakukan modifikasi. Modifikasi dilakukan dengan melihat nilai modification indices dari output AMOS yang berjumlah lebih dari 10. Hasil modifikasi dapat dilihat dari gambar 2. Adapun untuk penilaian goodness of fit yang baru dapat dilihat pada tabel 2 .

Tabel 1. Hasil Pengujian Goodness of FIT

\begin{tabular}{|l|l|l|l|}
\hline Goodness of fit index & Model & Cut off value & Keterangan \\
\hline$X^{2}$ Chi Square & 771,72 & (batas df: 390,38 ) & Bad Fit \\
\hline Sign Probability & 0,036 & $\geq 0,05$ & Bad Fit \\
\hline RMSEA & 0,128 & $\leq 0,08$ & Bad Fit \\
\hline GFI & 0,648 & $\geq 0,90$ & Bad Fit \\
\hline AGFI & 0,587 & $\geq 0,90$ & Bad Fit \\
\hline CMIN/DF & 2,23 & $\leq 2,00$ & Bad Fit \\
\hline TLI & 0,722 & $\geq 0,95$ & Bad Fit \\
\hline CFI & 0,745 & $\geq 0,95$ & Bad Fit \\
\hline
\end{tabular}

Sumber: Data primer diolah (2018)

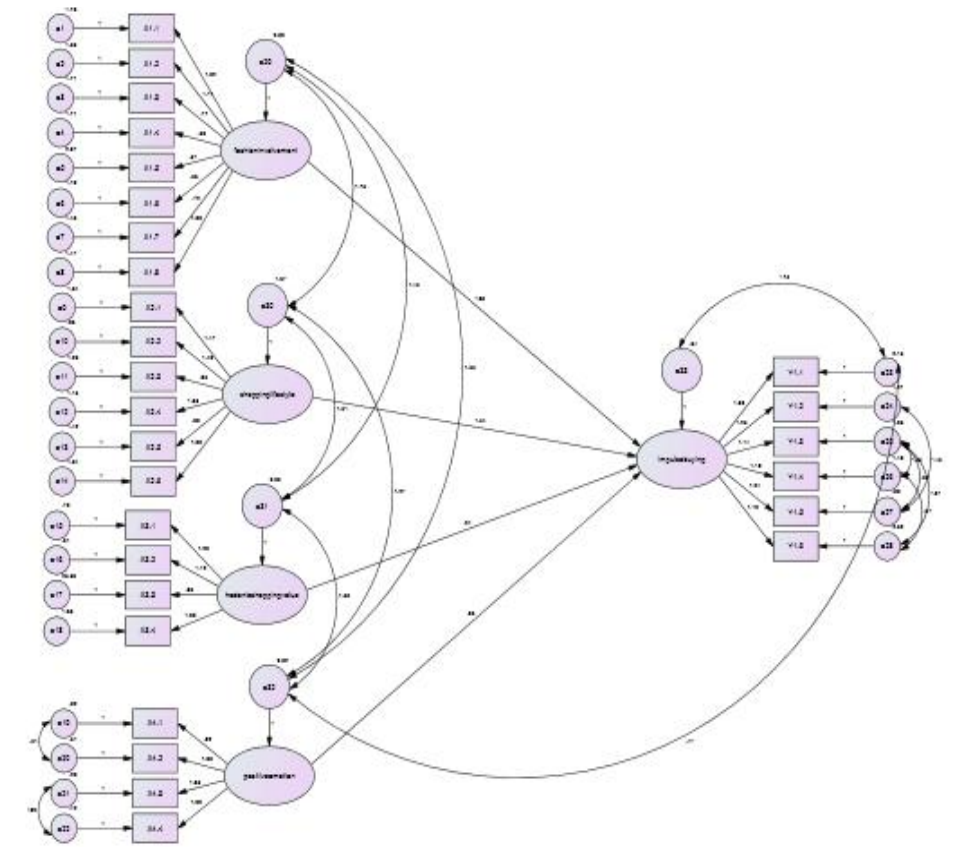

Gambar 2. Modifikasi Model

Sumber: Data primer diolah (2018) 
Tabel 2. Hasil Pengujian Goodness of FIT modifikasi model

\begin{tabular}{|l|l|l|l|}
\hline Goodness of fit index & Model & Cut off value & Keterangan \\
\hline$X^{2}$ Chi Square & 216,858 & (batas df: 390,38 ) & Baik \\
\hline Sign Probability & 0,107 & $\geq 0,05$ & Baik \\
\hline RMSEA & 0,077 & $\leq 0,08$ & Baik \\
\hline GFI & 0,779 & $\geq 0,90$ & Marginal \\
\hline AGFI & 0,730 & $\geq 0,90$ & Marginal \\
\hline CMIN/DF & 0,655 & $\leq 2,00$ & Baik \\
\hline TLI & 0,900 & $\geq 0,90$ & Baik \\
\hline CFI & 0,913 & $\geq 0,90$ & Baik \\
\hline
\end{tabular}

Sumber: Data diolah, (2018)

Tabel 3. Hasil pengujian Hipotesis

\begin{tabular}{|lll|c|c|}
\hline \multicolumn{2}{r}{} & Hipotesis & Estimate & CR \\
\hline Impulse buying & $<--$ & Fashion involvement &,- 074 & $-1,126$ \\
Impulse buying & $<---$ & Shopping lifestyle & 0,729 & $6,033^{*}$ \\
Impulse buying & $<---$ & Hedonic shopping value & 0,172 & $2,528^{*}$ \\
Impulse buying & $<---$ & Positive emotion & 0,178 & $2,660^{*}$ \\
\hline
\end{tabular}

* : Signifikan pada 0,05

Sumber: Data diolah, (2018)

\section{Pengujian Hipotesis}

Setelah model diinterpretasikan ke dalam bentuk persamaan maka langkah selanjutnya adalah pengujian hipotesis. Adapun langkah-langkah pengujian hipotesisnya adalah sebagai berikut:

1. Pengaruh variabel fashion involvement pada impulse buying pelanggan Duta Mall Banjarmasin. Berdasarkan hasil perhitungan dengan menggunakan program AMOS 21 didapatkan nilai critical ratio $-1,126<1,96$ dan $\mathrm{P}<0,26$. Maka dari itu dapat disimpulkan bahwa fashion involvement tidak berpengaruh signifikan dan negatif. Artinya semakin tinggi fashion involvement pelanggan Duta Mall Banjarmasin maka tidak berpengaruh terhadap impulse buying.

2. Pengaruh variabel shopping lifestyle pada impulse buying pelanggan Duta Mall BanjarmasinBerdasarkan hasil perhitungan dengan menggunakan program AMOS 21 didapatkan nilai critical ratio 6,033 > 1,96 dan $\mathrm{P}<0,05$. Maka dari itu dapat disimpulkan bahwa shopping lifestyle berpengaruh signifikan dan positif. Artinya semakin tinggi shopping lifestyle pelanggan Duta Mall Banjarmasin maka semakin tinggi pula impulse buying.

3. Pengaruh variabel hedonic shopping value pada impulse buying pelanggan Duta Mall Banjarmasin. Berdasarkan hasil perhitungan dengan menggunakan program AMOS 21 didapatkan nilai critical ratio 2,528 $>1,96$ dan $\mathrm{P}<0,05$. Maka dari itu dapat disimpulkan bahwa hedonic shopping value berpengaruh signifikan dan positif. Artinya semakin tinggi hedonic shopping value pelanggan Duta Mall Banjarmasin maka semakin tinggi pula impulse buying.

4. Pengaruh variabel positive emotion pada impulse buying pelanggan Duta Mall 
Banjarmasin. Berdasarkan hasil perhitungan dengan menggunakan program AMOS 21 didapatkan nilai critical ratio 2,660 > 1,96 dan $\mathrm{P}<0,05$. Maka dari itu dapat disimpulkan bahwa positive emotion berpengaruh signifikan dan positif. Artinya semakin tinggi positive emotion pelanggan Duta Mall Banjarmasin maka semakin tinggi pula impulse buying.

\section{KESIMPULAN DAN SARAN}

Kesimpulan

Berdasarkan pengujian yang dilakukan melalui metode analisis Structural Equation Modelling (SEM). Dari keempat variable diuji yaitu fashion involvement (x1), shopping lifestyle (x2), hedonic shopping value (x3), dan positive emotion (x4), hanya fashion involvement (x1) yang tidak berpengaruh signifikan dan negative terhadap impulse buying (Y). Hasil untuk variable fashion involvement (X1) terhadap impulsive buying (Y) ini tidak konsisten dengan penelitian Japarianto dan Sugiharto (2012) maupun Dhurup (2014).

\section{Saran}

Penelitian ini dpat dikembangkan pada penelitian selanjutnya dengan penambahan variable yang bisa mempengaruhi mpulsive buying seperti variabel pre-decision stage dan post-decision stage. Selain itu pemilihan tempat melakukan penelitian serta pemilihan populasi penelitian dapat diarahkan ke tempat lain seperti melihat tingkat pendapatan masyarakat Banjarmasin seperti misalnya penelitian pada masyarakat high income Banjarmasin.

\section{Keterbatasan}

Beberapa keterbatasan dalam penelitian ini antara lain pemilihan variable yang hanya fashion involvement, shopping lifestyle, hedonic shopping value dan positive emotion masih bisa dilengkapi dengan variable lain seperti pre-decision stage dan post-decision stage. Penelitian tidak menambahkan kategori salah satunya kategori pada tingkat pendapatan, karena peneliti di sini ingin melihat pengaruh variabel $\mathrm{X}$ terhadap $\mathrm{Y}$ pelanggan Duta Mall Banjarmasin secara umum pada semua kalangan.

\section{DAFTAR PUSTAKA}

Amiri, F., Jalal, J., Mohsen, S., and Tohid, A. 2012. Evaluation of Effective Fashionism Involvement Factors on Impulse Buying of Costumers and Condition of Interrelation Between These Factor. Journal of Basic and Applied Scientific Research. 2(9), pp. 9413-9419.

Arnold, \& Reynold. 2003. Hedonic Shopping Motivation. Journal of Retailling. Page (79) : $77-95$.

Astuti, R. D. \& Maria N. (2008). Perbedaan Pembelian secara Impulsif berdasarkan Tingkat Kecenderungan, Kategori Produk, dan Pertimbangan Pembelian. Jurnal Ichsan Gorontalo, 3, 1, 14411456.

Babin, B.J., Darden, W.R., \& Griffin, M. 1994.Work and/or Fun?Measuring Hedonic and Utilitarian Shopping Value. Journal of Consumer Research, 26(4): 644-656.

Banjarmasin Duta Mall Wikipedia bahasa Indonesia, https://id.m.wikipedia.org/wiki/Banjarm asin_Duta_Mall. Diakses 26 Juli 2015.

Browne, B. A., \& Kaldenberg, D. O. 1997. Conceptualizing Self Monitoring: Links to Meterialism and Product Involvement, Journal of Con-sumer Marketing, 14(1), pp. 31- 44.

Cenunk. 2009. Tantangan Baru Pemilik Merek, not plagiarism, diakses Maret 
2015 ,

http://kangcenunk.blogspot.com/2009/0

9/impulse-buying-tantangan-barupemilik.html.

Cobb, J.C., \& Hoyer, W.D. 1986. Planned Versus Impulse Purchase Behaviour. Journal of Retailing, 62(4): 384-409.

Darma, L.A., Japarianto, E. 2014. Analisa Pengaruh Hedonic Shopping Value Terhadap Impulse Buying Dengan Shopping Lifestyle dan Positive Emotion Sebagai Variabel Intervening Pada Mall Ciputra World Surabaya. Jurnal Manajemen Pemasaran. Vol 8, No 2.

Dhurup, M. 2014. Impulsive Fashion Apparel Consumption: The Role of Hedonism, Fashion Involvement and Emotional Gratification in Fashion Apparel Impulsive Buying Behaviour in a Developing Country. Journal of Social Sciences. Vol 5, No 8.

Engel, J. F., Blackwell, R.D. \& Miniard, P.W., 1995, Perilaku Konsumen, Jilid 1 (Edisi ke- enam), Jakarta: Binarupa Aksara.

Fairhurst, A. E., Good, L. K., \& Gentry, J. W. 1989. Fashion Involvement: an Instrument Validation Procedure. Clothing and Textiles Research journal, 7(3), pp. 10-14.

Ferdinand, A. 2006. Metode Penelitian Manajemen Pedoman Penelitian Untuk Penulisan Skripsi Tesis Disertai Ilmu Manajemen. Semarang : Universitas Diponegoro.

Hawkins, D.I., Best, R.J., \& Coney, K.A. 2001. Consumer Behaviour. (8thed.). New York: McGraw-Hill.

Herabadi, Astrid G., Bas Verplanken., \&. Ad van Knippenberg. 2009. Asian Journal of Social Psychology.12 20-31.

Japarianto, E., \& Sugiharto, S. 2011. Pengaruh Shopping Lifestyle dan Fashion Involvement Terhadap Impulse
Buying Behavior Masyarakat High Income Surabaya. Jurnal Manajemen Pemasaran, Vol 6 No 1, pp. 4-11.

Kapferer, J.N. \& Laurent, G. 1985. Measuring Consumer Involvement Profile, Journal of Marketing. 22(1), pp. 41-53.

Kertajaya, H. 2006. Hermawan Kertajaya on Marketing Mix. Bandung : Mizan.

Kim, H. 2005. Consumer Profiles of Apparel Product Involvement and Values. Journal of Fashion Marketing and Management, 9(2), pp. 207- 220.

Kotler, P., \& Keller, K. L. 2007. Manajemen Pemasaran. Edisi 12. PT. Indeks.

Kusuma, A. 2014. Pengaruh Fashion Involvement, Hedonic Consumption Tendency, dan Positive Emotion Terhadap Fashion Oriented Impulse Buying Kalangan Remaja di Surabaya. Jurnal Ilmiah Mahasiswa Universitas Surabaya. Vol.3 No.2.

Latan, H., \& Gudono. 2012. SEM Structural Equation Modeling. BPFE, Yogyakarta.

Malhotra, N., K. 2009. Riset Pemasaran Pendekatan Terapan. Edisi Keempat Jilid 1. PT Indeks.

Mulyaningrum, W. 2010. Analisis FaktorFaktor yang Mempengaruhi Impulse Buying Pada Merek Super T-Shirt (Studi pada Pengunjung Matahari Department Store Singosaren). Skripsi. Universitas Sebelas Maret Surakarta.

Noorhayati. 2012. Analisis Faktor-Faktor yang Mempengaruhi Keputusan Konsumen Berpindah Merek SIM Card (Kartu GSM Prabayar). Tesis. Unlam.

O'Cass, A., 2004. Fashion Clothing Consumption: Antecedents and Consequences of Fashion Clothing Involvement, European Journal of Marketing, 38(7), pp. 869-82.

Park, E. J., Kim, E. W., and Forney, J. C. 2006. A Structural Model of Fashion 
Oriented Impulse Buying Behavior, Journal of Fashion Marketing and Management, vol. 10, no. 4,pp: 433446.

Rachmawati, V. 2009. Hubungan Antara Hedonic Shopping Value, Positive Emotion, dan Perilaku Impulse Buying Pada Konsumen Ritel. pp. 193-198.

Rook, D.W. 1987. The Buying Impulse. Journal of Consumer Research, 14(2):189-199.

Rook, D.W., \& Gardner, M.P. 1993. In the mood: Impulse Buying's Affective antecedents. Research in Consumer Behaviour, 22:305-313.

Rook, D. W., \& Fisher, R. J. 1995. Normative Influences on Impulsive Buying Behaviour. The Journal of Consumer Research, 22:305-313.
Rook, D. W., and Fisher, R. J. 1995. Normative Influences on Impulsive Buying Behavior, Journal of Consumer Research, Vol. 22 (3), pp. 305-313.

Santoso, S. 2012. Analisis SEM Menggunakan AMOS. PT. Elex Media Komputindo: Jakarta.

Santoso, S. 2014. Konsep Dasar dan Aplikasi SEM dengan AMOS 22. PT. Elex Media Komputindo : Jakarta.

Solomon, M. R., \& Rabolt, N. J., 2009. Consumer Behavior in Fashion, Second Edition.

Tjiptono, F., Chandra, Y., \& Diana, A. 2004. Marketing Scales. Andi, Yogyakarta. 